\title{
Bioética: hechos, valores y deberes
}

\section{Padre Uriel Molina Oliú}

\section{Introducción}

Tal vez ningún otro tema como el del aborto ha causado tanta conmoción en el año 2007. Hay mucha polémica sobre el aborto y los protagonistas son la Iglesia Católica, los legisladores, los movimientos feministas y los teólogos. Si el tema sale a relucir una y otra vez, es señal de que no se ha captado bien.

Los bandos están bien definidos entre conservadores y liberales. Si se examinan los argumentos se constata que son argumentos de autoridad, por lo general. La Iglesia Católica insiste en su rechazo al aborto terapéutico y exige que los diputados mantengan su penalización, a pesar de vivir en un estado laico y sin pensar que para penalizar es necesario que haya un delito y cómo tipificar ese delito de aborto.

Para algunos diputados, lo que se quiere es abrir una puerta para continuar cometiendo crímenes contra niños indefensos. No ceden un solo centímetro a lo que llaman "protección de la vida desde la concepción”. Otros no están de acuerdo con el aborto como método anticonceptivo, pero sí respetan el derecho de la mujer de garantizar su vida y salud integral.

\section{Estado de la cuestión}

El aborto es un problema humano del que no se ocupa la Biblia. El punto medular es saber cuándo hay una vida humana en el desarrollo evolutivo del embrión. Sí a la vida, no a la muerte, es la posición de los obispos en Nicaragua en su reciente comunicado. Pero la vida y la paz están amenazadas de muerte. En Nicaragua como en todas partes, tremendas injusticias son perpetuadas y hay quienes se empeñan en mantener las causas de esas injusticias. Sabemos lo que representa en vidas humanas la guerra contra Irak y las políticas del FMI hacia los países del Tercer Mundo, pero no se percibe que estos temas sean objeto de comunicados por parte de la Conferencia Episcopal. Aún en los canales de televisión se nota la ausencia de una voz que llame a la conciencia y al análisis. En algunos programas radiales, el caso de la niña embarazada de nueve años no merece la atención de nadie. Hace mucha falta que la Palabra llegue a las situaciones concretas que vivimos.

Los obispos están clamando al cielo para que se haga una fuerte campaña contra el aborto, pero no exhortan a que nuestro pueblo se embarque en una gran campaña contra la muerte, a pesar de que estamos circundados de muerte. Porque eso es lo que está pasando con las víctimas del Nemagón, con los pescadores de langosta de la Costa Atlántica, con las víctimas 
de asbestosis de San Rafael del Sur, con los cortadores de café en el Norte, con los miles de niños sin escuela, a pesar de los grandes esfuerzos que se están haciendo para mejorar la educación. Y el estado de la salud deja mucho que desear, sobre todo por el alto costo de los exámenes como el TAC, la resonancia magnética, los ultrasonidos, etc. Y por el enorme precio de las medicinas.

Son miles de miles los que ven acortada su vida porque, en vez de consumir 2,400 calorías por día, se ven obligados a consumir sólo 1,200. Por otra parte existen miles de personas que consumen alimentos en exceso, que derrochan medicamentos, que habitan en casas lujosas, muchas de ellas sin pagar luz ni agua. Hay acaparadores de tierras que despojan a los campesinos. Y las donaciones que han llegado para paliar los desastres naturales como el Mitch, fueron a parar a bolsillos privados. Ese tipo de gente dice estar a favor de la vida $y$, con intransigencia terrible, se prestan a defender la vida del feto como digna, sagrada e intocable. Me pregunto: ¿Qué defienden en última instancia, estos adversarios del aborto terapéutico? Y algunos altos dignatarios se han enzarzado en defensas públicas de funcionarios corruptos, sin el menor pudor, y cuando tuvieron la oportunidad de decir su palabra sobre la niña embarazada por violación, se rasgaron las vestiduras, proclamando a los cuatro vientos el derecho a la vida del no nacido.

Por otra parte se ignoran los resultados de la bioética como ciencia que se ocupa de estas cuestiones delicadas.

\section{Qué pretendo con este escrito}

No es mi propósito defender lo indefendible. La eliminación del feto es un mal. Se dan, sin embargo, determinadas circunstancias en las que una u otra persona invoca el derecho de no verse obligada a aceptar la vida del prenacido por algunos graves inconvenientes o por razones de menor peso.

Pero no está ahí el núcleo del problema. Mientras no decidamos apuntarnos a un proyecto de convivencia universal, fundado en la justicia y en la fraternidad, no estaremos planeando con justicia y coherencia el problema del aborto. Resulta sospechosa e inconsciente toda campaña antiabortista que no vaya acompañada de un compromiso de lucha contra toda mentalidad hegemónica y belicista.

\section{El aporte de la bioética como ciencia}

La bioética como ciencia reciente actúa como puente entre dos riberas: una, la de los hechos científicos y, la otra, la de los "valores" que todos defendemos y que nos confieren para dar sentido a nuestras vidas. Cuando se producen conflictos entre hechos y valores se pueden ver cuáles son nuestros deberes.

Hechos y valores progresan a una velocidad vertiginosa. Pero se necesita saber cuáles son nuestros deberes. Esa es tarea propia de la ética para reflexionar y tomar decisiones acerca de lo que se debe o no hacer. 


\section{Hechos, valores y deberes}

Hecho es todo lo que percibimos con los sentidos, pero los "hechos científicos" intentan convertir en hechos cosas que no son directamente percibidas por los sentidos. Según el filósofo francés A. Comte, a partir del siglo XIX comenzaría la tercera fase de la historia de la humanidad, en la que toda realidad se ha de interpretar sobre la base de hechos y tan sólo de hechos, dejando fuera toda clase de especulaciones y abstracciones metafísicas. Pero hay cosas que no son hechos y que, sin embargo, forman parte esencial de la vida humana. Son los valores que debemos tener en cuenta a la hora de tratar cualquier cuestión sobre los confines de la vida.

Es un hecho universal que el ser humano tiene valores. Son quizás la parte más importante de la vida humana. El mundo de los valores se basa en el mundo de los hechos pero sin identificarse con ellos.

Si tenemos hechos y valores, la cuestión será: ¿Cuáles son nuestros deberes? Los valores cambian a menudo, incluso en nosotros mismos. A menudo hay conflicto de valores. Un valor es aquello que no puede faltar en un mundo bien ordenado. Por ejemplo, en la Escritura aparece el Reino de Dios con cuatro valores: verdad, justicia paz y amor. Pero ese mundo ideal no existe. El deber es realizar los valores en cuanto sea posible en este mundo.

Un médico sabe que no debe mentir, pero hay momentos en que no puede decir la verdad. En un conflicto de valores uno tiene que ceder ante otro, contando con las circunstancias. Y esto se da con frecuencia cuando se trata de temas tan complejos como los que afectan el comienzo y el final de la vida humana.

\section{Aplicaciones a los confines de la vida}

Los datos científicos provocaron una auténtica revolución en el manejo de la vida humana. Ha cambiado la concepción de la sexualidad y de la reproducción con la píldora anticonceptiva. Este hecho fue la base de la separación entre la sexualidad y reproducción. Hoy se da una ética de la sexualidad y una ética de la reproducción, cuando antes ambas formaban parte de una única ética.

Otro hecho fundamental fue el relacionado con los problemas de la herencia. No se sabía el motivo de por qué los hijos se parecían a sus progenitores. En la primera mitad del siglo XX se comprueba que el ser humano posee unos caracteres fenotípicos que se transmiten como una información desde el ser generador al ser generado. Hay una unidad de información que se conoce con el nombre de gen.

Había que buscar esas unidades de información, los genes, que se suponía que se encontrarían en estructuras complicadas como las proteínas, difíciles de manejar en un laboratorio. En los años cuarenta se descubrió que esa información se hallaba en estructuras más manejables, como los “ácidos nucleicos”.

Así se comienza a conocer la base científica de la información genética. En los años 70 apareció la técnica del $\mathrm{ADN}$ recombinante, que permite cambiar la información genética 
de las especies. Es posible manipular la vida biológica, lo que genera muchos conflictos de valores. O jugamos a ser "dioses", sustituyendo a Dios, o prolongamos la obra de la creación con su inteligencia.

En la genética, los hechos generan muchos problemas, ya sea en el origen de la vida, con temas como la clonación, la manipulación de células madre, las diversas técnicas de reproducción humana asistida, el diagnóstico prenatal o el aborto de los nacidos prematuros, o en el final de la vida, como la eutanasia, el suicidio asistido, la limitación del esfuerzo terapéutico, la sedación terminal, los cuidados intensivos, etc.

Podríamos decir que el ser vivo pasa por una fase "constituyente" antes de llegar a la "suficiencia constitucional". Por eso es muy aventurado sacralizar los genes porque son el resultado de un proceso evolutivo y no definen absolutamente al ser humano, siendo "condición necesaria pero no suficiente".

Una cuestión importante es saber si lo que llamamos "inteligencia" está presente desde el

primer momento o no, para lo cual han surgido varias repuestas. Una respuesta sería pensar que la inteligencia es una cualidad fenotípica que se gana o se pierde (caso Alzheimer). Pero, ¿cuál es el soporte de ese trazo fenotípico? Caben dos posibilidades. Una sería creer que hay un elemento constitutivo del ser humano, que sería lo que se ha dado en llamar "alma". Es la teoría del "creacionismo"que intenta explicar por qué los seres humanos generan eso que se llama vida del espíritu o cultura. Pero, ¿cuándo se genera esa "alma”? La repuesta católica afirma que se produciría en el primer momento, lo cual no deja de tener problemas.

Otra repuesta sería la emergencia, es decir, la que dice que las realidades físicas y químicas van interactuando entre sí produciéndose saltos desde la cantidad y calidad, haciendo así aparecer cualidades nuevas, como en las mezclas químicas. De ahí que considerar que esta cualidad de la inteligencia es cuando menos, el resultado de un proceso complejo.

Por tanto, si la vida personal específicamente humana, con inteligencia, es una propiedad estructural, la solución sería óptima. En el caso del embrión, la vida puede entrar en conflicto con otros valores sean como sean. Podemos pensar en los casos en que está despenalizado el aborto: consecuencia de una violación, peligro para la salud física o psíquica de la madre y graves malformaciones del feto. Son situaciones de conflictos de valores. Esto puede verse claramente en uno de los temas más conflictivos, como es el del aborto, en el que la sociedad aparece claramente dividida entre dos actitudes de la pro-vida y la pro-decisión.

La primera afirma que hay que proteger los valores, pero analizando las posturas se ve que están polarizadas, optando por los extremos que casi siempre son los menos aconsejables. Los pro-vida afirman que el ser humano lo es desde el primer momento de la concepción y que eliminarlo se considera delito penal, en tanto los pro-elección piensan que la mujer es dueña de su cuerpo y es ella quien debe decidir.

La vía intermedia es una actitud más importante: la "gestión" responsable de la sexualidad y de la reproducción. Probablemente lo mejor sería no criminalizar ni trivializar nada, si no hacerse responsable, es decir, promover la responsabilidad social con la vida y con los embriones humanos. 
La mayor parte de los conflictos éticos están relacionados con el final de la vida. Todos los seres humanos nacemos y morimos y conforme nos vamos acercando a los extremos, los trazos que nos caracterizan se van difuminando hasta llegar a una situación de penumbra. La primera cuestión es: ¿Cuándo muere una persona? La única manera de saberlo con seguridad es cuando su cuerpo se descompone, pero por lo terrible del espectáculo, todas las culturas buscaron otros síntomas para determinar la muerte antes de la descomposición. El síntoma más común fue el de la parada respiratoria, es decir, la ausencia del latido cardíaco. Pero este criterio ha dejado de ser válido. A partir de los años cincuenta surgió otro criterio, el de muerte encefálica o cerebral, produciéndose el hecho curioso de que esta muerte cerebral no tiene que coincidir con la muerte caardiopulmonar o viceversa. Más aún, si hay alguien que se hallé en muerte encefálica se le pueden extraer los órganos para una donación. Es esencial que su corazón siga latiendo para que sus órganos se hallen en "condiciones fisiológicas". Pero no hay respuestas absolutas. 